\title{
Mass Spectrometric Study of Photoionization. I. Apparatus and Initial Observations on Acetylene, Acetylene- $d_{2,}$ Benzene, and Benzene- $d_{6}^{*}$
}

\author{
Vernon H. Dibeler and Robert M. Reese
}

(April 9, 1964)

\begin{abstract}
A windowless vacuum ultraviolet monochromator and mass spectrometer are combined for the study of photoionization processes in the energy range 2000 to $600 \AA$ (6 to $21 \mathrm{eV}$ ). Details of the apparatus and techniques of operation are given and results are reported for an initial study of acetylene, acetylene- $d_{2}$, benzene, and benzene- $d_{6}$. Ionization energies of 11.406 and $11.416 \mathrm{eV}$ are obtained for the $1_{\pi_{u}}$ electron of $\mathrm{C}_{2} \mathrm{H}_{2}$ and $\mathrm{C}_{2} \mathrm{D}_{2}$, respectively. Vibrational levels of the ground state of the ion are observed with quantum intervals of $1855 \mathrm{~cm}^{-1}\left(\mathrm{C}_{2} \mathrm{H}_{2}\right)$ and $1775 \mathrm{~cm}^{-1}\left(\mathrm{C}_{2} \mathrm{D}_{2}\right)$. Ionization energies for the $e_{1 g}(\pi)$ electron of $\mathrm{C}_{6} \mathrm{H}_{6}$ and $\mathrm{C}_{6} \mathrm{D}_{6}$ are determined to be $9.24_{2}$ and $9.24_{5} \mathrm{eV}$, respectively. Quantum intervals for vibrational levels of the ground state ions are apparently equal for the two isotopic molecules and estimated to be $800 \mathrm{~cm}^{-1}$. A second onset of ionization is observed at $11.5_{3} \mathrm{eV}$ for $\mathrm{C}_{6} \mathrm{H}_{6}$ and at $11.5_{9} \mathrm{eV}$ for $\mathrm{C}_{6} \mathrm{D}_{6}$. Results agree well with spectroscopic data.
\end{abstract}

\section{Introduction}

Nearly monochromatic photon beams have been used for many years $[1]^{1}$ to study photoionization processes in low-pressure gaseous systems. The recent addition of mass spectrometric techniques $[2,3]$ to identify unequivocally the ions produced in the photoionization process has obviated any uncertainty in the chemical composition and has shown that, at least in principle, considerable information can be obtained on the upper energy states of polyatomic molecules and the dissociation processes of ions [4].

In surmounting the experimental difficulties of combining vacuum ultraviolet spectroscopy and mass spectrometry, Hurzeler et al. [2] used a lithium fluoride window to isolate a hydrogen-discharge photon source from the high-vacuum regions of the monochromator and mass spectrometer. Thus, although the photon source included a broad energy range, the absorption of the window limited the measurements to wavelengths longer than $1040 \AA$ $(E<11.9 \mathrm{eV})$.

Weissler et al. [3] used no windows in their apparatus but employed a repetitive low-pressure spark to produce a widely spaced line spectrum. For some of the molecules studied, the lack of a sufficient number of emission lines in the vicinity of an onset of ionization prevented establishing that onset to better than $\pm 30 \AA( \pm 0.5 \mathrm{eV})$. Also, the presence in the mass spectrometer of background gases from the photon source resulted in undesirable effects on ion formation.

*This work was supported in part by Project Defender of Advanced Research Projects A gency, Department of Defense and by the Atomic Energy Commission.

1 Figures in brackets indicate the literature references at the end of this paper.
A combined mass spectrometer-vacuum ultraviolet monochromator designed to avoid the above difficulties was recently completed and is being applied to the study of photoionization processes in the energy range 2000 to $600 \AA$ ( 6 to $21 \mathrm{eV})$. Details of the arrangement, the method of operation and the results of some observations on acetylene and benzene are given in the following sections. ${ }^{2}$

\section{Experimental Details}

Measurements were made by means of the apparatus shown schematically in figure 1. A photon source $(L)$, a vacuum ultraviolet monochromator $(M)$, and a mass spectrometer $(N)$ are combined essentially in the manner first described by Hurzeler et al. [2]. An important exception, however, is the complete absence of absorbing windows to isolate high pressure regions from the monochromator and mass spectrometer. Thus, the entire vacuum ultraviolet region is accessible.

\subsection{Monochromator}

The Seya-Namioka type [5] instrument with a 1-m focal length was built to specifications by the McPherson Instrument Co., Acton, Mass. The photon exit arm to which the mass spectrometer is appended is nonmagnetic stainless steel. Usual materials are used elsewhere. Three optical entrance slits, sized 50,100 , and $500 \mu$, are mounted on a turret located at $S_{1}$ (fig. 1) which can be rotated from outside the vacuum.

2 A brief announcement of this work appears in J. Chem. Phys. 40, 2034 (1964). 


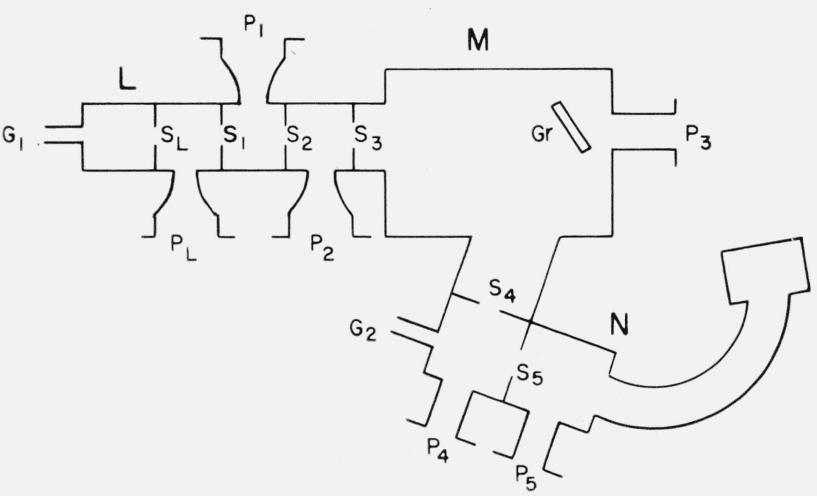

Figure 1. Schematic diagram showing the arrangement of photon source (L), monochromator (M), mass spectrometer $(\mathrm{N})$, slits $(\mathrm{S})$, and pumping ports $(\mathrm{P})$.

$S_{L}$, photon source slit, $0.3 \times 6 \mathrm{~mm} ; S_{1}, S_{4}$, entrance and exit optical slits, $0.1 \times 10$ $\mathrm{mm} ; S_{2}, S_{3}$, differential pumping slits, $2 \times 4 \mathrm{~mm}$ and $4 \times 5 \mathrm{~mm}$, respectively; $S_{5}$ ion defining slit, $0.5 \times 10 \mathrm{~mm}$. $P_{L}, 8 \mathrm{l} / \mathrm{s}$ mechanical pump; $P_{1}, 400 \mathrm{l} / \mathrm{s}$ Heraeus Roots, $80 \mathrm{l} / \mathrm{s}$ forepump; $P_{2}, 700 \mathrm{l} / \mathrm{s}$ oil diffusion, $80 \mathrm{l} / \mathrm{s}$ forepump; $P_{3}, 1400 \mathrm{l} / \mathrm{s}$ oil diffusion, $40 \mathrm{l} / \mathrm{s}$ forepump; $P_{4}, P_{5}$, liq. $\mathrm{N}_{2}$ traps, $\mathrm{Hg}$ diffusion and forepumps.

The concave, tripartite grating $(G r)$ supplied by Bausch and Lomb contains 600 grooves per $\mathrm{mm}$ in a ruled area $56 \times 96 \mathrm{~mm}$. It is blazed for $1500 \AA$ and coated with magnesium fluoride. With the grating in place, the first-order dispersion of the monochromator is stated by the manufacturer to be 16.6 $\AA / \mathrm{mm}$. The grating is rotated manually or at any one of 12 scanning speeds by a synchronous motor The wavelength is read from a counter coupled directly to the grating drive. Adjustments are provided for correcting the linearity and the calibration of the scale. Wavelengths can be selected manually to better than $1 \AA$ when traveling in one direction.

The monochromator is provided with two differential pumping ports $\left(P_{1}, P_{2}\right)$ separated by slits $\left(S_{2}\right.$, $\left.S_{3}\right)$, and located immediately behind the entrance optical slit $\left(S_{1}\right) . \quad P_{1}$ is evacuated by a $400 \mathrm{l} / \mathrm{s}$ (at 1 torr) ${ }^{3}$ Heraeus-Roots pump; $P_{2}$, by a $700 \mathrm{l} / \mathrm{s}$ (at $10^{-3}$ torr) oil-diffusion pump. Each is backed by an $80 \mathrm{l} / \mathrm{s}$ (free air) mechanical pump. The grating chamber is evacuated $\left(P_{3}\right)$ by a $1400 \mathrm{l} / \mathrm{s}$ (at $10^{-3}$ torr) oil-diffusion pump backed by a $40 \mathrm{l} / \mathrm{s}$ mechanical pump. Freon or water-cooled baffles, suitable gate valves, and vacuum gages are provided at each port. Seals in high-vacuum regions are made with O-rings fabricated of fluorocarbon elastomer. Other O-ring's are made of Buna-N.

The base pressure of the monochromator is about $3 \times 10^{-7}$ torr. With hydrogen at a nominal pressure of 10 torr flowing into $G_{1}$ and with slit sizes as indicated in figure 1 , the system maintains a pressure differential of $10^{5}$ between photon lamp and monochromator chamber. With the lamp operated at higher pressures (>100 torr), additional pumping is provided at $P_{L}$ by means of an $8 \mathrm{l} / \mathrm{s}$ (free air) mechanical pump. This results in a pressure differential of $10^{6}$ between lamp and monochromator.

${ }^{3} 1$ torr-1/760 atm-133.32 newtons-meter-2 $\left(\mathrm{N} / \mathrm{m}^{2}\right)$.

\subsection{Mass Spectrometer}

Analysis and detection of the photoions is accomplished by means of a conventional 15-cm radius of curvature, single focusing, sector-field instrument fabricated of Inconel and stainless steel. All vacuum seals are gold wire O-rings. The ion-source housing and analyser tube are separated by the ion defining slit $\left(S_{5}\right)$ and are separately pumped through $5-\mathrm{cm}$ gate valves, by liquid nitrogen traps and mercury diffusion pumps. The untrapped speed of the diffusion pumps is reported by the manufacturer to be $501 / \mathrm{s}$ at $10^{-3}$ torr. Under conditions indicated above, the pressure differentials between lamp and ion source and between lamp and analyser tube are of the order of $10^{8}$ and $10^{9}$, respectively. Thus with a lamp pressure of 400 torr, the pressure in the analyser tube of the mass spectrometer is about $4 \times 10^{-7}$ torr.

The ion-source housing and analyser tube are supported by the photon exit arm of the monochromator. Locating pins in the vacuum flanges maintain appropriate alinement of the photon beam, ion source, and analyser. The optical exit-slit mount is electrically insulated from the monochromator. The slit assembly is attached to the ionization chamber by screws thereby forming one wall of the chamber. The slit assembly (and ionization chamber) is attached to the mount by means of a self-locating dovetail connection. Interchangeable slit assemblies to match the entrance optical slits are available.

Figure 2 is a photograph of the detached ion source showing the ionization chamber and the ion accelerating and focusing plates. The dovetailed exit optical-slit assembly forming one wall of the ionization chamber is visible in the right foreground. The sample inlet tube and a filament assembly and anode used for electron impact measurements are removed for the photograph.

Figure 3 shows the ion-source housing with the cover plate removed and the source mounted in place. 'The direction of the photon beam is toward the observer and approximately perpendicular to the plane of the photograph. 'The large slit in the center permits the diverging photon beam to leave the ionization chamber without striking metal surfaces until it reaches the photon monitor mounted on the coverplate. The photoions are accelerated out of the ionization chamber and toward the right of the figure. The chosen geometry of the system (orientation of photon slit relative to ion slits) results in ease of construction and alinement. Unfortunately, it also results in a smaller usable ionization volume compared with that in the geometry used by Hurzeler et al. [2].

Gas samples are admitted to the ionization chamber by means of an all-metal gas handling system, a 2-liter reservoir, and gold pinhole leak. Mass analysis is performed at a constant ion accelerating voltage of $2 \mathrm{kV}$ by varying the magnetic field. The latter, set to focus a selected ion at the collector, is monitored by means of a Bell model 240 incre- 


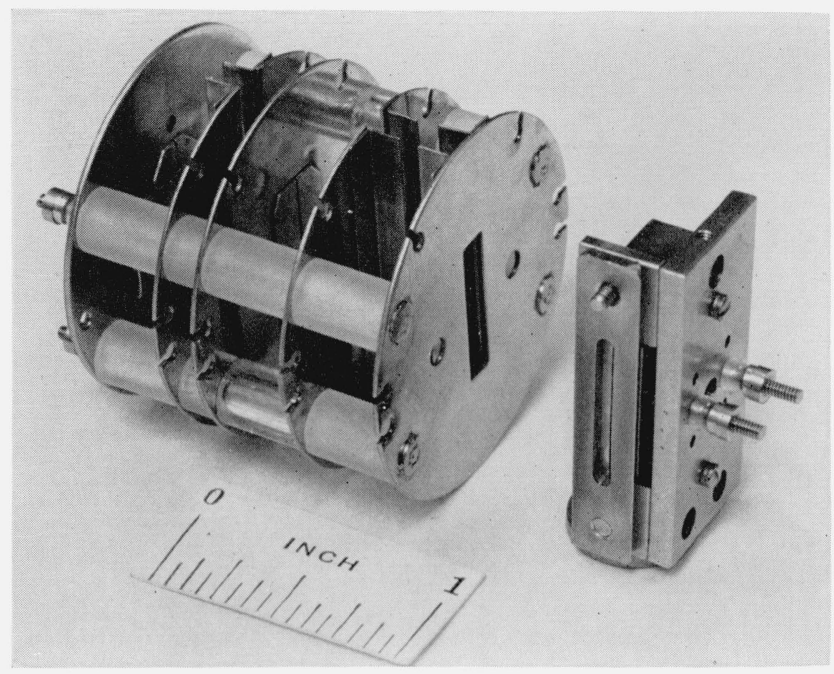

Figure 2. Ionization chamber and ion accelerating plates.

The photon slit in the wall of the ionization chamber is just visible in the dovetailed mount. Two threaded rods are the ion-repeller connections.

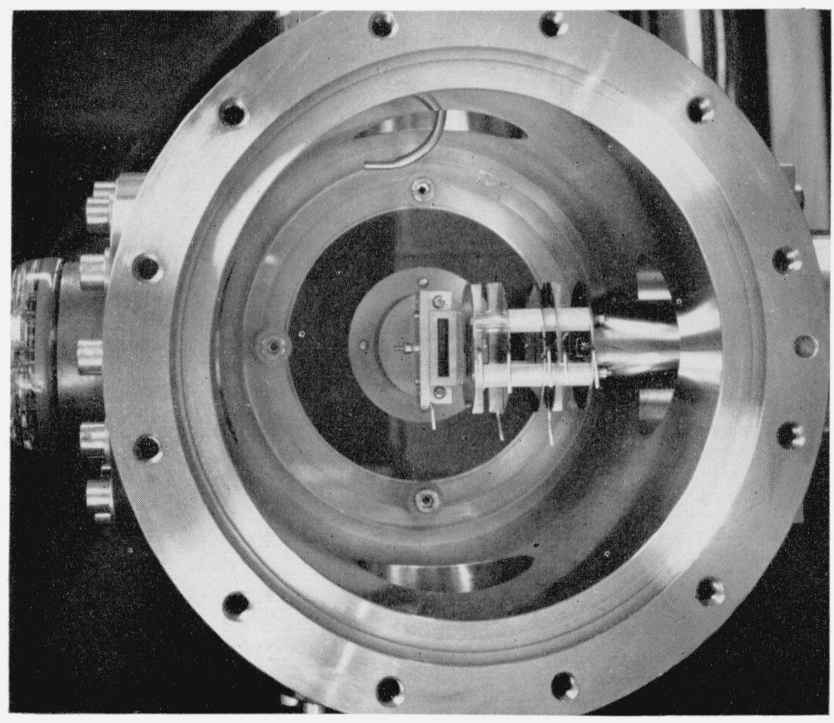

Figure 3. Ion-source housing with cover removed to show the mounted ionization chamber and ion accelerating plates.

The photon beam leaves the ion chamber by the large rectangular slit and strikes the detector mounted on the cover plate. Photoions are accelerated toward the right of the figure. The pumping port at the bottom of the housing and the ras-inlet tube at the top are visible. In use, a flexible Teflon tube conand the gas-iniet tube at the top are visible. In use,

mental gaussmeter and recorded by a strip-chart recorder. Ion currents are measured with an electron multiplier, amplifier, and scaler. Maximum ion currents are of the order of 100 counts/s or $10^{-17} \mathrm{~A}$. Within $20 \AA(\sim 0.2 \mathrm{eV})$ below threshold, maximum background currents are of the order of 1 count/s.

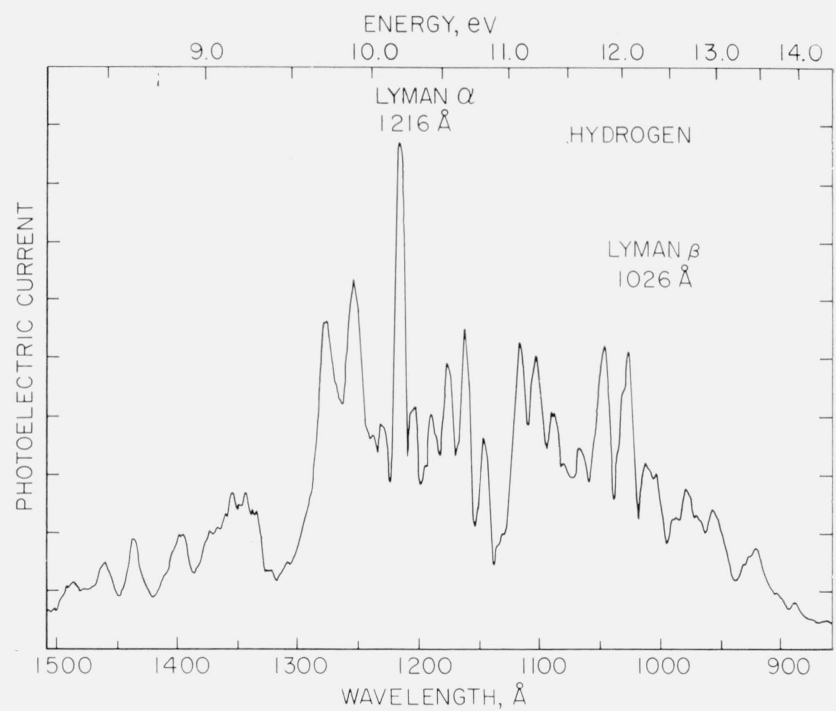

FiguRE 4. Tracing of the recorded photoelectric current from the photon detector as a function of wavelength for $a d-c$ hydrogen discharge at a pressure of a few torr.

Entrance and slits are $100 \mu$ and the scan rate is $100 \AA / \mathrm{min}$.

\subsection{Photon Source}

Two types of lamps are used as photon sources. The first is a Hinteregger type similar to that described by Huffman, Tanaka, and Larrabee [6]. In operation, highest commercial purity cylinder gases without further purification enter through $G_{1}$ and exit through the differential pumping ports. The discharge is excited by charging energy storage capacitors from an unregulated high-voltage d-c supply through a current-limiting resistor. For hydrogen at a pressure of a few torr, a steady operating current of $250 \mathrm{~mA}$ is obtained with about $600 \mathrm{~V}$ across the lamp. Figure 4 is a tracing of the photoelectric current from the photon detector as a function of the wavelength. The spectrum is scanned at the rate of $100 \AA / m i n$. Entrance and exit optical slits are $100 \mu$ and no correction is made for the photoeletric efficiency of the detector. The Lyman- $\alpha$ line is easily identified and the relatively broad energy range of 1500 to $900 \AA$ (8 to $14 \mathrm{eV}$ ) shown here indicates the general usefulness of this source of radiation. However, the large and frequent changes in photon intensity with wavelength characteristic of the many-lines emission spectrum superimposed on the Lyman continuum is a definite disadvantage.

Contrary to the above, the well-known rare-gas continua [7, 8, 9] provide comparatively uniform intensity with wavelength, although over shorter energy ranges. A recent study [6] has given details of best conditions for producing the helium continuum using a d-c discharge.

Tanaka and Zelikoff [10] first used microwave excitation in a windowless tube to obtain an emission continuum in xenon. Subsequent work [11] appeared so promising that a windowless microwave source 


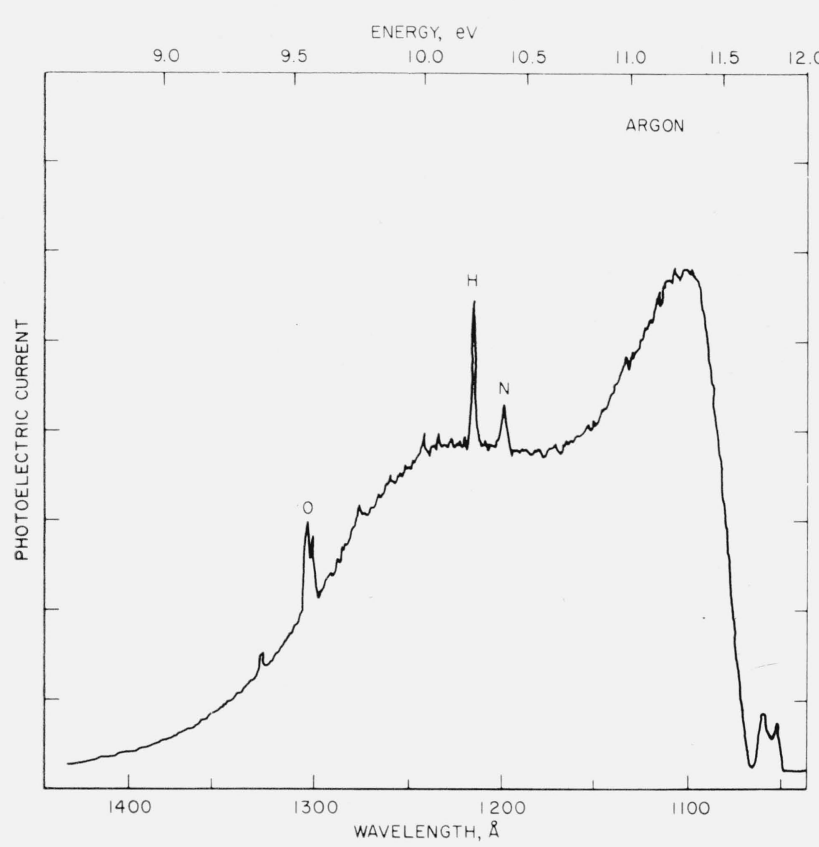

Figure 5. Tracing of the recorded photoelectric current of the photon monitor as a function of wavelength for the argon continuum at 400 torr.

Slits are $100 \mu$ and the scan rate is $100 \AA / \mathrm{min}$.

was constructed for the present research. A 13-mm o.d. Vycor tube with 1-mm walls was sealed by means of epoxy resin into a hole drilled through the center of a water-cooled aluminum-alloy flange. The flanged end of the tube was terminated by a $0.3 \times 6-\mathrm{mm}$ slit in a thin stainless-steel sheet. The lamp was mounted with the slit end a few millimeters in front of the entrance optical slit of the monochromator. With argon flowing through the lamp at about 400 torr, the discharge is excited by a Raytheon model PGM-100, $2450 \mathrm{MHz}, 250$ to $800 \mathrm{~W}$, cw generator. Figure 5 shows a tracing of the continuum recorded for $100-\mu$ slits at a rate of $100 \AA / \mathrm{min}$. The useful range in the present experiments extends from 1400 to $1070 \AA$ (8.8 to $11.6 \mathrm{eV})$. Small impurity peaks are usually observed and serve as convenient fiducial points for calibration of the wavelength scale. The stability of the lamp as measured by the photon intensity at any point on the continuum was usually better than \pm 1 percent at least during the time required to obtain the ion count.

Figure 6 shows a tracing of the argon doublet resonance lines at 1066.7 and $1048.2 \AA$ obtained at low pressure (a few torr) to check the resolving power of the monochromator. The lines are scanned at a rate of $10 \AA /$ min using $100-\mu$ slits. The apparent half-width of the lines is about $2 \AA$ which is consistent with a resolving power of $1.7 \AA$ calculated from the slit dimensions. The actual line width, of course, is much narrower.

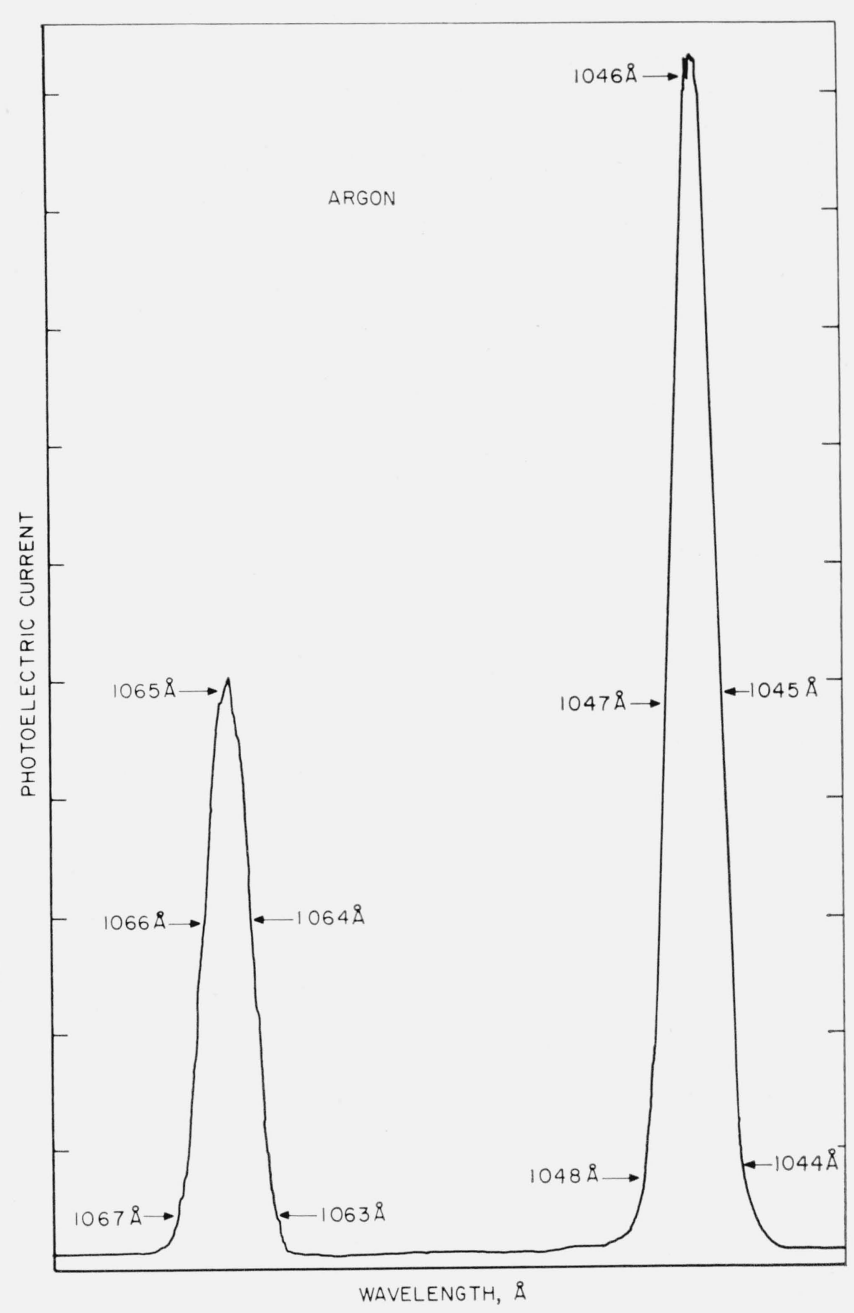

Figure 6. Tracing of the photoelectric current of the photon monitor as a function of wavelength for the argon doublet resonance lines at low pressure (a few torr).

The slits are $100 \mu$ and the scan rate is $10 \AA / \mathrm{min}$. The wavelength scale is uncorrected.

\subsection{Photon Detector}

Initial measurements were made using a sodium salicylate-coated photomultiplier tube [12]. However, the quantum efficiency of the coating was apparently affected by exposure to hydrocarbon samples or residual pumping vapors and it was discarded in favor of a photoelectric detector. The cathode of the latter was made from a tungsten ${ }^{4}$ sheet $10 \times 40 \times 0.1 \mathrm{~mm}$ taken from the laboratory stock and cleaned chemically. The anode was several $0.1-\mathrm{mm}$ Nichrome wires mounted close to the surface and biased $+45 \mathrm{~V}$ with respect to the cathode. The photoelectrons leaving the cathode were measured by means of a vibrating reed electrometer and recording potentiometer. The detector

4 In preliminary experiments, cathodes were made of a variety of metals including rhenium, platinum, nichrome, and gold. No significant advantages over tungsten were observed. 
was enclosed in an open-mesh grid to shield it from the ion accelerating field in the ion source. Nevertheless, there remained the possibility of accelerating photoelectrons into the ionization chamber. This was shown to be of negligible importance by changing the field penetration, and introducing auxiliary electric and magnetic deflecting fields.

Although the quantum efficiency of photoelectron emitters varies with the wavelength, the general form of the function is known for many metals $[1,13]$. Alternatively, the function may be approximated from an assumed or measured photoionization efficiency curve. Previous workers have used the photoionization of NO for this purpose [2]. In the present work, the relative quantum yield was assumed to follow the curves for untreated tungsten $[14,15]$. In addition, the absolute yield at two wavelengths was estimated (probably within a factor of 2) by the following separate experiment: A krypton resonance lamp similar to that described for xenon by Wilkinson and Tanaka [11] and the photon detector used in this work were mounted at opposite ends of a cell containing parallel-plate electrodes for ion measurement [16]. With the cell evacuated, light from the resonance lamp operating at an arbitrary intensity was allowed to strike the detector and the photoelectric current was measured. Without disturbing the lamp, the cell was filled with NO under conditions of nearly total photon absorption $[16,17$,$] . Thus, the observed ion current between$ the electrodes was taken as a measure of the total number of photons entering the cell. The resultant nominal ratio of electrons/photon was one electron for $10^{3}$ photons. From the above measurement it was also possible to estimate that with a bandwidth of $2 \AA$, a maximum photon flux of $10^{12}$ quanta/s was produced at the entrance slit of the monochromator with the present windowless photon sources. Furthermore, with the same resonance lamp in place of the regular photon source of the monochromator, it was observed that the maximum photon flux through the ionization chamber was of the order of $10^{10}$ quanta $/ \mathrm{s}$.

\subsection{Experimental Procedure}

Briefly, a photoionization efficiency curve is obtained as follows: The photon source is excited and allowed to run for several minutes. The photoelectric current-versus-wavelength curve is obtained for the emission spectrum of the source, noting the apparent wavelengths of identifiable lines. Using a photon energy well above ionization threshold, the ion beam is focused at the ion collector. The grating is then turned to about $20 \AA$ below threshold for the first observation, taking about 100 counts per point up to threshold. Usually 5000 or more counts are taken for each point above threshold. Thus the probable counting error of each point in this region is about 1.4 percent. The photon intensity and magnetic field strength are continuously monitored and recorded. The sample pressure is noted periodically and a correction for pressure drop in the sample reservoir is applied to the final data.

\subsection{Materials}

Ordinary acetylene, with a purity of 99.6 percent, as stated by the supplier, was obtained from the Matheson Company. Ordinary benzene was research-grade material from the laboratory stock. Acetylene- $d_{2}$ and benzene- $d_{6}$ were obtained from Merck, Sharpe, and Dohme, Montreal and had a stated isotopic purity of 99 atom percent D. Mass spectrometric analysis confirmed this value and indicated a comparable chemical purity.

\section{Results and Discussion}

\subsection{Acetylene}

Photoionization efficiency curves for the $\mathrm{C}_{2} \mathrm{H}_{2}{ }^{+}$and the $\mathrm{C}_{2} \mathrm{D}_{2}{ }^{+}$ions of acetylene and acetylene- $d_{2}$ obtained by means of the hydrogen discharge as a photon source are shown in figures 7 and 8 , respectively.

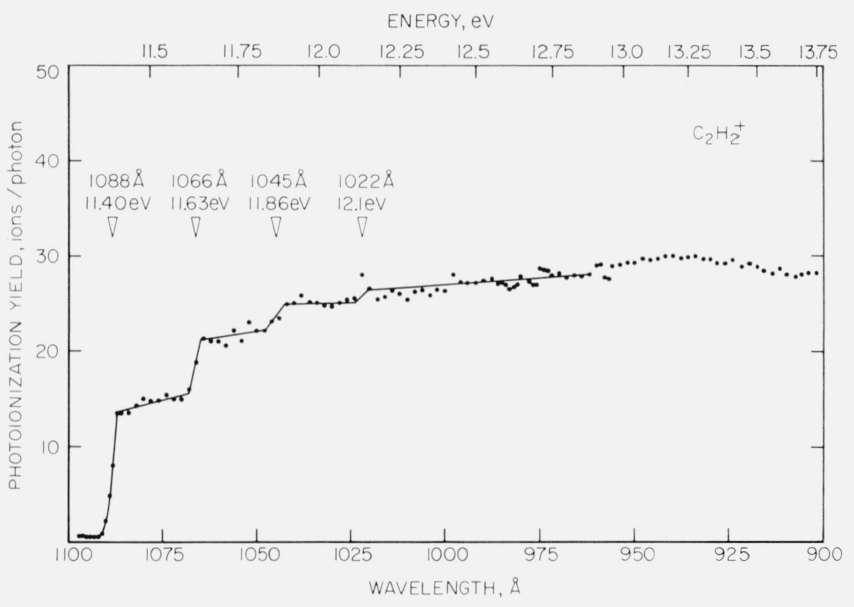

Figure 7. Photoionization efficiency curve for the $\mathrm{C}_{2} \mathrm{H}_{2}+$ ion of acetylene obtained by means of the hydrogen discharge as a photon source.

Thresholds of ionization are indicated in angstroms and electron volts. All photoionization yie!ds are in arbitrary units.

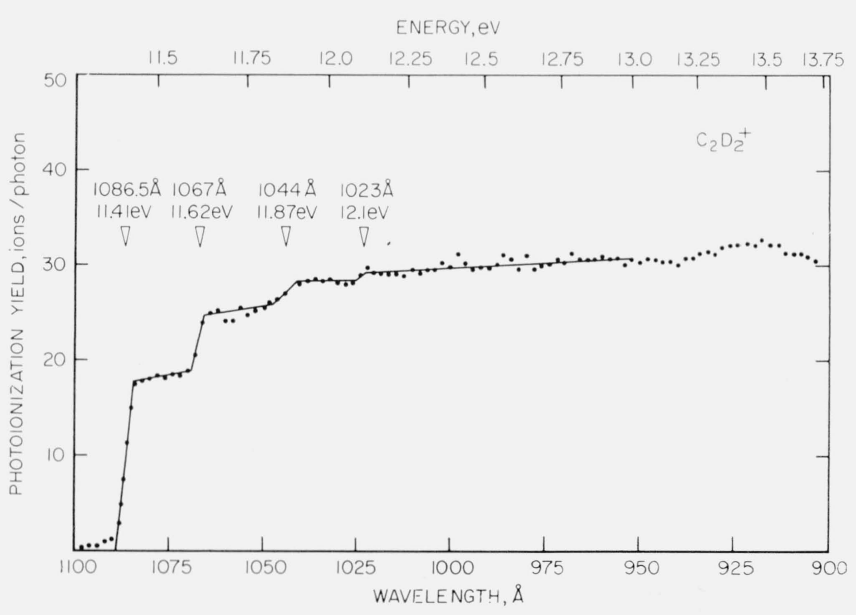

Figure 8. Photoionization efficiency curve for the $\mathrm{C}_{2} \mathrm{D}_{2}+$ ion of acetylene- $\mathrm{d}_{2}$ obtained in the same manner as figure $\%$. 
The photoionization yield (ions/photon) is plotted as a function of the wavelength in angstroms. The equivalent energy in electron volts is also given. The more fundamental property, the photoionization cross section, could not be determined under the conditions of these experiments. However, Nicholson [18] has shown that even for moderate absorption the resulting error in plotting the photoionization yield is small.

The first sharp rise in both curves is interpreted as the onset for the $0-0$ transition for the lowest energy electron. Following Nicholson, the point of steepest ascent is chosen as the ionization energy. For acetylene, the arithmetic mean of five determinations of the first ionization energy is $1087.0 \pm 0.6 \AA$ or $11.406 \pm 0.006 \mathrm{eV}$ where the uncertainty is the computed probable error for a single determination. For acetylene- $d_{2}$, the analogous values are 1086.0 $\pm 0.6 \AA$ or $11.416 \pm 0.006 \mathrm{eV}$.

Two Rydberg series in the vacuum ultraviolet absorption spectrum of acetylene were identified by Price [19]. Both series lead to an ionization energy of $11.41 \mathrm{eV}$. An identical value is reported by Watanabe [20,21] using photoionization without mass analysis.

An ionization potential of $11.40 \mathrm{~V}$ for $\mathrm{C}_{2} \mathrm{H}_{2}$ was reported by Lossing, Tickner, and Bryce [22] using an electron-impact method. These authors also reported the value of $11.39 \mathrm{~V}$ for $\mathrm{I}\left(\mathrm{C}_{2} \mathrm{D}_{2}\right)$. However, they considered the ionization potentials of the isotopic molecules to be indistinguishable within the limits of their measurement (ca $0.1 \mathrm{~V}$ ). From the present measurements it is apparent that the ionization energy of $\mathrm{C}_{2} \mathrm{D}_{2}$ is greater than that of $\mathrm{C}_{2} \mathrm{H}_{2}$ by about $0.01 \mathrm{eV}$ as is expected from differences in zero-point energy.

The general shapes of the ionization efficiency curves for the two molecules are similar. In both cases, the first onset is followed at nearly uniform intervals by several well-defined onsets. For $\mathrm{C}_{2} \mathrm{H}_{2}{ }^{+}$, the intervals are approximately $0.23 \mathrm{eV}$ or 1855 $\mathrm{cm}^{-1}$. For $\mathrm{C}_{2} \mathrm{D}_{2}{ }^{+}$, the intervals are not entirely consistent but appear to average about $0.22 \mathrm{eV}$, or $1775 \mathrm{~cm}^{-1}$. These ionization potentials are summarized in table 1.

Wilkinson [23] has obtained high resolution absorption spectra for acetylene and acetylene- $d_{2}$ in the vacuum ultraviolet. Four electronic transitions were identified. One of these, designated $3 \mathrm{R}$, is of a Rydberg type and probably involves a linear upper state. The $\nu_{2}$ (carbon-carbon stretching frequency) of the $3 R$ state was found to be $1848 \mathrm{~cm}^{-1}(0.23 \mathrm{eV})$ for $\mathrm{C}_{2} \mathrm{H}_{2}$ and $1720 \mathrm{~cm}^{-1}(0.21 \mathrm{eV})$ for $\mathrm{C}_{2} \mathrm{D}_{2}$. The agreement with the vibrational intervals shown in the figures and in table 1 is very satisfactory. Furthermore, the relative intensities of the vibrational steps observed in the present work are entirely consistent with Wilkinson's observations. The simple vibrational structure and the apparently equally spaced vibrational levels indicate a linear ground state of the ion as suggested by Wilkinson.
TABLE 1. Summary of ionization energies for acetylene and acetylene- $\mathrm{d}_{2}$

\begin{tabular}{|c|c|c|}
\hline \multirow{2}{*}{ Orbital and vibrational transition } & \multicolumn{2}{|c|}{ Ionization energy } \\
\hline & $\mathrm{C}_{2} \mathrm{H}_{2}$ & $\mathrm{C}_{2} \mathrm{D}_{2}$ \\
\hline 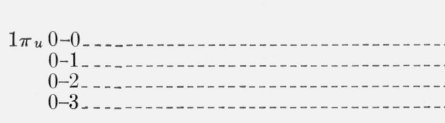 & $\begin{array}{l}e V \\
\text { a } 11.406 \pm 0.006 \\
\text { b } 11.63 \pm 0.05 \\
11.86 \pm 0.05 \\
12.1 \pm 0.1\end{array}$ & $\begin{array}{c}e V \\
\text { a } 11.416 \pm 0.006 \\
\text { b } 11.62 \quad \pm 0.05 \\
11.87 \pm 0.05 \\
12.1 \quad \pm 0.1\end{array}$ \\
\hline
\end{tabular}

a Arithmetic mean and computed probable error for five independent measurements.

b Arithmetic mean and maximum deviation from the mean.

The ground-state electronic configuration of acetylene can be expressed [24] as:

$$
\mathrm{C}_{2} \mathrm{H}_{2}:\left(\sigma_{g} 1 s_{c}\right)^{2}\left(\sigma_{u} 1 s_{c}\right)^{2}\left(2 \sigma_{g}\right)^{2}\left(2 \sigma_{u}\right)^{2}\left(3 \sigma_{g}\right)^{2}\left(1 \pi_{u}\right)^{4},{ }^{1} \Sigma_{g}{ }^{+} .
$$

It is very probable that the ionization energy of the $1 \pi_{u}$ electron is $11.41 \mathrm{eV}$. However, the ionization energy of the $3 \sigma_{g}$ electron is still a matter of conjecture. Recent calculations [25] result in an approximate value of $18.6 \mathrm{eV}$ for the orbital energy of the $3 \sigma_{g}$ electron. An electron impact study [26] using simulated conditions of a monoenergetic electron beam has not confirmed that value. However, Lindholm [27], using charge exchange, has observed just two electronic states of acetylene: one appearing at $11.4 \mathrm{eV}$ and the other at about $15.5 \mathrm{eV}$ with a remarkable gap in the distribution function between 12 and $15.5 \mathrm{eV}$. From the present work it is only concluded that no optically allowed transition occurs at wavelengths above $900 \AA(\mathrm{E}<14 \mathrm{eV})$ and that the ionization energy of the $3 \sigma_{g}$ electron is at least $14 \mathrm{eV}$. Furthermore, in the absence of any suggestion of autoionized Rydberg terms it is probable that the orbital energy is several electron-volts above $14 \mathrm{eV}$.

\subsection{Benzene}

Photoionization efficiency curves for the $\mathrm{C}_{6} \mathrm{H}_{6}{ }^{+}$ and the $\mathrm{C}_{6} \mathrm{D}_{6}+$ ions of benzene and benzene- $d_{6}$ are shown in figure 9. The photon source for wavelengths above $1070 \AA$ is the argon continuum. The hydrogen emission spectrum is used for wavelengths between 1070 and $900 \AA$. Although not shown beyond $1035 \AA$, the curves are continuous, slowly rising, and essentially smooth to $900 \AA$.

For the first ionization energy of benzene, the arithmetic mean and computed probable error of three determinations are $1341.5 \pm 1.0 \AA$, or $9.24_{2}$ $\pm 0.01 \mathrm{eV}$. For benzene- $d_{6}$, the values are 1341.0 $\pm 1.0 \AA$, or $9.24_{5} \pm 0.01 \mathrm{eV}$. In both cases, the first onset is followed by several onsets ascribed to vibrational levels of the ground-state ion. Figure 10 shows an enlarged-scale plot of the initial portion of the curve for $\mathrm{C}_{6} \mathrm{D}_{6}{ }^{+}$. Although less well defined than in the case of the acetylenes, the quantum intervals for the benzenes are estimated to be 0.1 $\mathrm{eV}\left(\sim 800 \mathrm{~cm}^{-1}\right)$ and in the present experiments are apparently equal for the two isotopic molecules. 


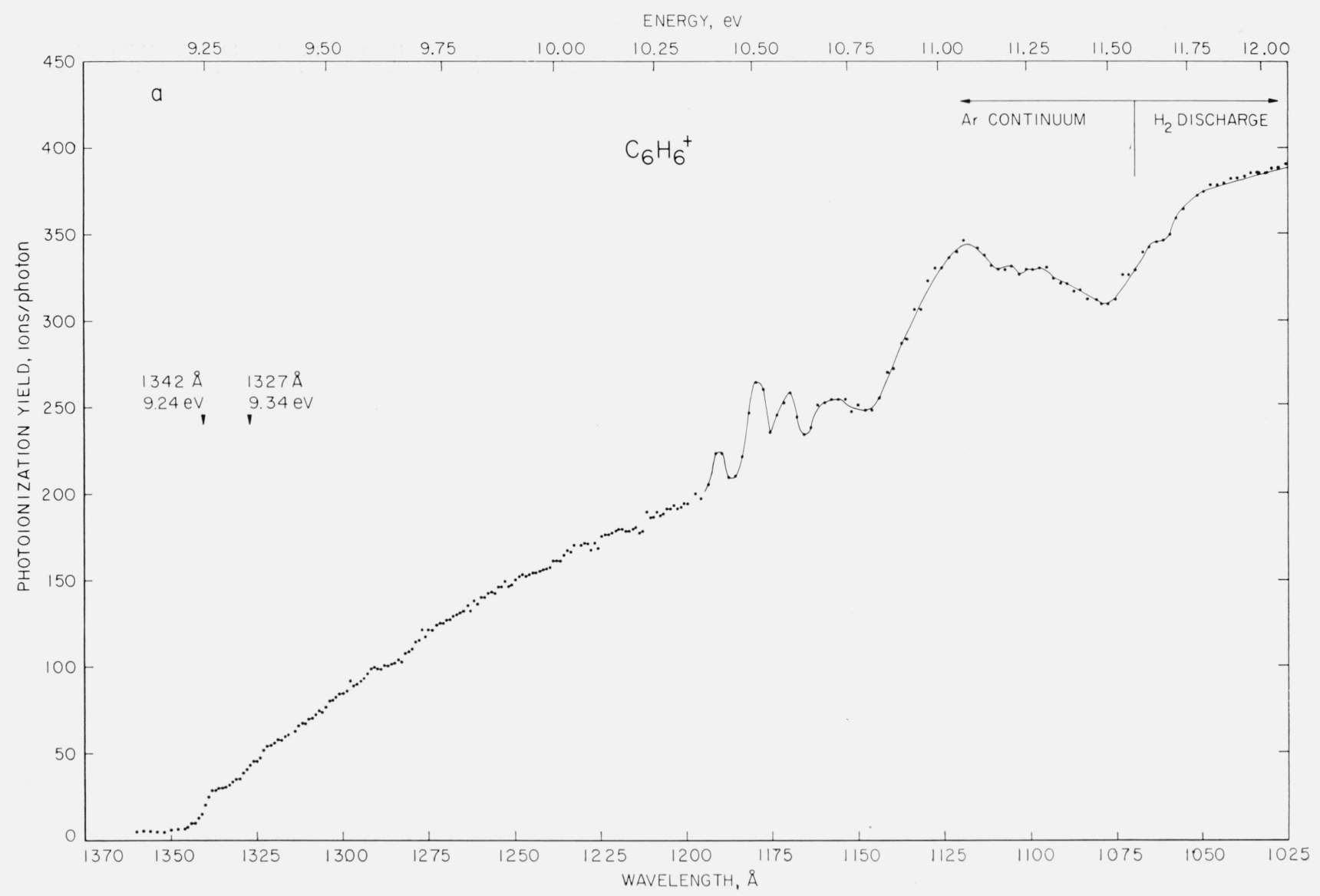

Figure 9. a, b. Ionization efficiency curves for the $\mathrm{C}_{6} \mathrm{H}_{6}+$ ion of benzene and the $\mathrm{C}_{6} \mathrm{D}_{6}{ }^{+}$ion of benzene- $\mathrm{d}_{6}$ obtained by the use of the argon continuum and the hydrogen emission spectrum.

Threshold energies for the ground-state ions are indicated.

Rydberg series in benzene were first analyzed by Price and Wood [28]. More recently, Wilkinson [29] obtained high-resolution absorption spectra of benzene and benzene- $d_{6}$ and identified four Rydberg series all converging to the same ionization limits: $9.247 \pm 0.002 \mathrm{eV}\left(\mathrm{C}_{6} \mathrm{H}_{6}\right)$ and $9.251 \pm 0.002 \mathrm{eV}$ $\left(\mathrm{C}_{8} \mathrm{D}_{6}\right)$. These were assigned to the ionization of the lowest energy $\pi$ electron. The present measurements are in good agreement with these and with recent photoionization measurements made without mass analysis [29].

The general shapes of both curves are quite similar. A Rydberg term with well-defined vibrational structure is observed in the region of $1180 \AA\left(\mathrm{C}_{6} \mathrm{H}_{6}\right)$ and $1175 \AA\left(\mathrm{C}_{6} \mathrm{D}_{6}\right)$. The "peak" shapes indicate autoionization or predissociation from these levels. A less well-defined term or terms appears in the region of $1120 \mathrm{~A}$ leading to the second ionization threshold at $1075 \AA\left(11.5_{3} \mathrm{eV}\right)$ for $\mathrm{C}_{6} \mathrm{H}_{6}$ and $1070 \AA$ $\left(11.5_{9} \mathrm{eV}\right)$ for $\mathrm{C}_{6} \mathrm{D}_{6}$. These observations are generally consistent with the recent measurements by Tanaka and coworkers [30] and the suggested assignment of the second ionization energy to an electron from an $\left(a_{2 u}\right) \pi$-electron molecular orbital. The general features of an absorption curve of $\mathrm{C}_{6} \mathrm{H}_{6}$ reported by Goto [31] also show similarities with the present results.

From the second ionization potential $(11.5 \mathrm{eV})$ and the usual Rydberg equation, series members leading to that ionization potential are calculated: one to appear at about $1175 \AA(10.5 \mathrm{eV})$ and the other to appear very close to the first ionization limit. Both members have been observed by Price and Wood [28]. Wilkinson [29] reports a strong absorption doublet for benzene (1342.5 $\AA$ and $1341.5 \AA$ ) and for benzene- $d_{6}$ (1335.4 $\AA$ and $1338.2 \AA$ ) which are very close to the onset of ionization. As no autoionization peaks are observed at the onset of ionization in the present work, it may be concluded that these transitions are to a neutral molecule rather than to the molecule ion.

Electron impact studies of benzene [32, 33] have given indications of several electronic states above the ground state of the ion. At present, the only firmly established onset would appear to be that of the $\left(a_{2 u}\right) \pi$-electron at $11.5 \mathrm{eV}$. 


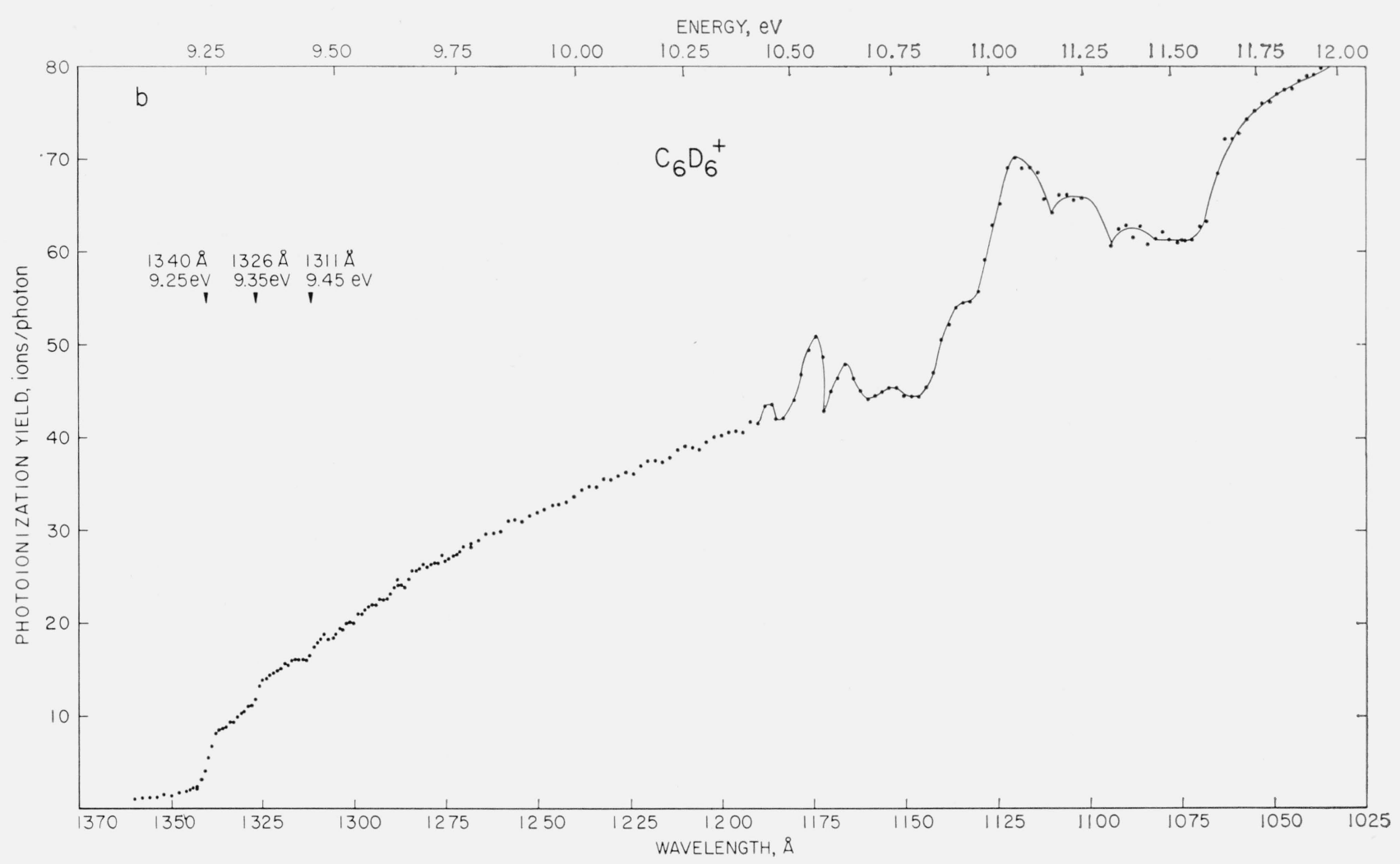

Figure 9-Continued.

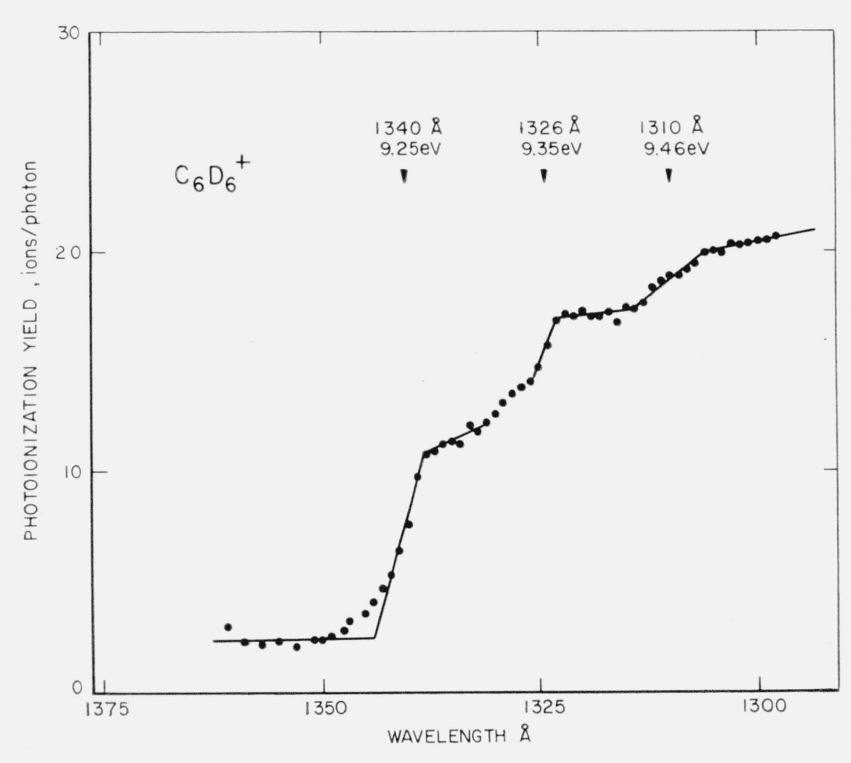

Figure 10. Enlarged-scale plot of the initial portion of an ionization efficiency curve for the $\mathrm{C}_{6} \mathrm{D}_{6}{ }^{+}$ion showing the vibrational intervals of the ground state of the ion.
We acknowledge the advice and assistance of W. R. Shields, K. E. McCulloh, and M. E. Wacks in construction and maintenance of the apparatus. We are also indebted to M. Krauss and P. G. Wilkinson for helpful discussions of results and to H. M. Rosenstock and F. L. Mohler for encouragement throughout the course of the work.

\section{References}

[1] G. L. Weissler, Handbuch der Physik, Springer-Verlag, Berlin, 1956, Vol. 21, p. 304.

[2] H. Hurzeler, M. G. Inghram, and J. D. Morrison, J. Chem. Phys. 28, 76 (1958).

[3] G. L. Weissler, J. A. R. Samson, M. Ogawa, and G. R. Cook, J. Opt. Soc. Am. 49, 338 (1959).

[4] W. A. Chupka, J. Chem. Phys. 30, 191 (1959).

[5] M. Seya, Sci. of Light ₹, 8 (1952); T. Namioka, ibid. 3, $15(1954)$

[6] R. J. Huffman, Y. Tanaka, and J. C. Larrabee, J. Opt. Soc. Am. 52, 851 (1962).

[7] J. J. Hopfield, Phys. Rev. 35, 1133 (1930); ibid, 36, 784 (1930).

[8] Y. Tanaka, J. Opt. Soc. Am. 45, 710 (1955)

[9] Y. Tanaka, A. S. Jursa, and F. J. LeBlanc, J. Opt. Soc. Am. 48, 304 (1958).

[10] Y. Tanaka, and M. Zelikoff, Phys. Rev. 93, 933 (1954); J. Opt. Soc. Am. 44, 254 (1954).

[11] P. G. Wilkinson and Y. Tanaka, J. Opt. Soc. Am. 45, 344 (1955). 
[12] F. S. Johnson, K. Watanabe, and R. Tousey, J. Opt. Soc. Am. 41, 702 (1951).

[13] S. W. Wonssowski, A. W. Sokolow, and A. S. Wexler, Fortschr. Physik, 4, 115 (1956); ibid. 4, 216 (1956).

[14] H. E. Hinteregger and K. Watanabe, J. Opt. Soc. Am. 43, 604 (1953).

[15] Reference [1], p. 354.

[16] E. C. Y. Inn, Spectrochimica Acta \%, 65 (1955)

[17] K. Watanabe, F. F. Marmo, and E. C. Y. Inn, Phys. Rev. 91, 1155 (1953).

[18] A. J. C. Nicholson, J. Chem. Phys. 39, 954 (1963).

[19] W. C. Price, Phys. Rev. 47, 444 (1935).

[20] K. Watanabe, J. Chem. Phys. 26, 542 (1957).

[21] T. Nakayama and K. Watanabe, J. Chem. Phys. 558 (1964)

[22] F. P. Lossing, A. W. Tickner, and W. A. Bryce, J. Chem. Phys. 19, 1254 (1951).

[23] P. G. Wilkinson, J. Mol. Spectroscopy 2, 387 (1958).

[24] R. S. Mulliken, Can. J. Chem. 36, 10 (1958).
[25] A. D. McLean, J. Chem. Phys. 32, 1595 (1960).

[26] J. E. Collin, Bull. Soc. Chim. Belg. 71, 15 (1962).

[27] E. Lindholm, Proceedings of the Eleventh Annual Conference on Mass Spectrometry and Allied Topics, San Francisco, Calif. May 19-24, 1963.

[28] W. C. Price and R. W. Wood, J. Chem. Phys. 3, 439 (1935)

[29] P. G. Wilkinson, J. Chem. Phys. 24, 917 (1956); Can. J. Phys. 34, 596 (1956).

[30] M. F. Amr El-Sayed, M. Kasha, and Y. Tanaka, J. Chem. Phys. 34, 334 (1961).

[31] K. Goto, Sci. of Light, 11, 116 (1962)

[32] R. E. Fox and W. M. Hickam, J. Chem. Phys. 22, 2059 (1954).

[33] J. D. Morrison, J. Chem. Phys. 22, 1219 (1954).

(Paper 68A4-289) 


\section{Publications of the National Bureau of Standards*}

\section{Selected Abstracts}

General application of Youden's rank sum test for outliers and tables of one-sided percentage points, T. A. Willke, $J$. Res. NBS 68B(Math. and Math. Phys.), No. 2, (Apr.June 1964). 75 cents.

The rank sum test for outliers advanced by W. J. Youden provides a method for detecting if the measurement distribution of any one of a group of objects has a mean significantly different from the rest. This paper discusses a more general application of the rank sum procedure which permits a similar test on other parameters, such as the variance, with the same tables. Tables of the critical values of the extreme rank sum and the corresponding significance levels for one-sided tests are given in this paper to supplement similar tables for two-sided tests already published.

Fitting $y=\beta x$ when the variance depends on $x, J$. Van Dyke, J. Res. NBS 68B (Math. and Math. Phys.), No. 2. (Apr.June 1964). 75 cents.

This paper presents some results concerning the selection of a method for estimating the slope of a straight line through the origin. For fitting the line $y=\beta x$ when the variance of $y$ is proportional to $x^{p}$, it is well known that the best estimate of $\beta$ depends on $p$. In practice, however, only integer values of $p$ would be convenient to work with. One of the estimators appropriate for $p=0,1,2$ would probably be used if the value of $p$ were in fact fractional, or if it were only approximately known. This paper provides some guides for choosing the best among these estimators in a particular situation.

Formulas for the best estimators of $\beta$ and their variances are given. Estimators of $\beta$ appropriate for integer values of $p$ are compared in the case when $p$ is not integral, but is known, and in the case when $p$ is only approximately known. Estimation of the variances of estimators of $\beta$ is considered. Finally, some results are given on the effect of the spacing of the $x$ values on the comparison of the estimators.

A spectrographic interferometer, R. H. Lee and J. W. Warwick, Radio Sci. J. Res. NBS/USNC-URSI, 68D, No \% (July 196.4). $\$ 1.00$.

The paper includes a description of the principal novelties of a swept-frequency interferometer operation between 7.6 and. $41 \mathrm{MHz}$ at the High Altitude Observatory in Boulder, Colo., since July 1959. Records of Jupiter's decametric radio emission, and of a solar harmonic type III burst are included, with a cursory description of the corner-reflector antenna system used to feed the receiver. The receiver employs unique "minimum detection" circuits to reduce the deleterious effects of telecommunications stations on detection of the weak astronomical signals of interest to us. For interferometry, the receiver uses an inversion circuit to present both negative and positive fringes as darkening on the final record, and to sharpen fringe crossovers.

Shielding against gamma rays, neutrons, and electrons from nuclear weapons, A review and bibliography, J. H. Hubbell and L. V. Spencer, NBS Mono. 69 (Feb. 24, 1964), 30 cents. The problem of predicting dose rates and of estimating the effectiveness of shielding from radiations resulting from nuclear explosions is discussed. A number of existing calculations and supporting experiments regarding the penetration and diffusion of gamma rays, neutrons, and electrons through air and bulk materials are summarized. Indications are given of gaps in such input information. A selection of 485 references from the unclassified literature is presented, of which 388 are cataloged as to source geometry and energy, absorber material and configuration, type of data presented, and method of calculation or experimental technique.
These cataloged references include radiation field studies ranging from the point-source infinite-medium situation up through such complicated geometries as foxholes, shelters, and conventional structures. The other references are of a general or review nature or contain input spectral data.

Inspection of processed photographic record films for aging blemishes, C. S. McCamy, NBS Handb. 96 (Jan. 24, 1964), 25 cents.

Inspections of microfilms have recently revealed blemishes which apparently developed 2 to 20 years after the films were processed. Most of the blemishes are small spots, usually reddish or yellowish in color, ranging from about 15 to 150 microns across. These blemishes have been classified on the basis of size, shape, color, and character. This publication describes and gives colored illustrations of the various types, describes the method of observing them, and recommends sampling procedures for microfilm inspectors. The cause, the exact mechanism of formation of the various types, and generally accepted preventive measures are not as yet known. This publication is intended to promote uniform terminology, inspection, and reporting.

Safe handling of radioactive material, NBS Handb. 92 (Mar. 9, 1964), 40 cents (Supersedes Handb. 42).

This handbook presents recommendations of the National Committee on Radiation Protection and Measurements. It is designed to help the user of radioactive materials to handle radionuclides without exposing himself or others to doses in excess of maximum permissible limits. It provides background material on the principles of radiation protection and then gives recommendations on personnel, physical safeguards, procedural safeguards, instrumentation, transportation of radioactive material and radioactive waste disposal.

Synthesis and stability of bismutotantalite, stibiotantalite and chemically similar $\mathrm{ABO}_{4}$ compounds, R. S. Roth and J. L. Waring, Am. Mineralogist 48, 1348-1356 (Nov-Dec. 1963)

Bismutotantalite $\left(\mathrm{BiTaO}_{4}\right)$ and stibiotantalite $\left(\mathrm{SbTaO}_{4}\right)$ have been synthesized by appropriate heating of the mixed oxides in sealed Pt tubes. Bismuth trioxide and antimony trioxide have been mixed with niobium, tantalum, and vanadium pentoxides and the resulting $\mathrm{ABO}_{4}$ compounds are discussed with respect to structure type and stability of the various phases.

Polymorphism of silver iodide, G. Burley, Am. Mineralogist 48, 1266-1276 (Nov.-Dec. 1963).

The polymorphic relationship of silver iodide at atmospheric pressure has been reinvestigated using high temperature x-ray diffraction, differential thermal analysis and conductometric techniques. A hexagonal (wurtzite type) and a face-centered cubic (zincblende or sphalerite type) phase can exist between liquid helium temperature and $147^{\circ} \mathrm{C}$. The latter is metastable over this entire range. From $147^{\circ} \mathrm{C}$ to the melting point at $555{ }^{\circ} \mathrm{C}$ a disordered body-centered cubic phase is the stable modification. The methods of preparation and transformation are summarized and a qualitative explanation of phase stabilization is presented.

Equilibrium ${ }^{\top}$ pressures of oxygen over $\mathbf{M n}_{2} \mathrm{O}_{3}-\mathbf{M n}_{3} \mathrm{O}_{4}$ at various temperatures, E. M. Otto, J. Electrochem. Soc. 111, No. 1, 88-92 (Jan. 1964).

The equilibrium represented by the equation $6 \mathrm{Mn}_{2} \mathrm{O}_{3}(\mathbf{c})$ $=4 \mathrm{Mn}_{3} \mathrm{O}_{\mathrm{c}}(\mathrm{c}, a)+\mathrm{O}_{2}$ has been studied by measuring the equilibrium pressures of oxygen over $\mathrm{Mn}_{2} \mathrm{O}_{3}-\mathrm{Mn}_{3} \mathrm{O}_{4}$. From the data obtained in the $1132^{\circ}$ to $1247^{\circ} \mathrm{K}$ range |studied $\Delta H^{\circ}$ and $\Delta S^{\circ}$ were calculated for the reaction at $1200^{\circ} \mathrm{K}$ to be $41.2 \pm 1.2 \mathrm{k}$ cal and $32.9 \pm 1.0 \mathrm{cal} / \mathrm{deg}$, respectively. These 
constants can be used in the equation

$$
-4.5758 \log p \mathrm{O}_{2}(\mathrm{~atm})=41,200 / T-32.9
$$

to relate $\log p \mathrm{O}_{2}$ and temperature of the system in the above mentioned range with no appreciable additional error. A slight extrapolation showed $p \mathrm{O}_{2}=1$ atm at $1252^{\circ} \mathrm{K}$. The above $\Delta H$ and $\Delta S$ values were converted to $298.15^{\circ} \mathrm{K}$ and compared with those in the literature. A new entropy $S^{\circ}{ }_{298}=36.8 \mathrm{cal} / \mathrm{deg}$ for $\mathrm{Mn}_{3} \mathrm{O}_{4}$ and a new heat of formation $\Delta H f_{298}=-228.7 \mathrm{k}$ cal for $\mathrm{Mn}_{2} \mathrm{O}_{3}$ are indicated from analysis of data in the literature and the present data. This value of entropy of $\mathrm{Mn}_{3} \mathrm{O}_{4}$ is higher by $1.3 \mathrm{cal} / \mathrm{deg}$ (roughly $\mathrm{R} 1 n 2$ ) than the value taken from the literature.

On the relaxation of the hard-sphere Rayleigh and Lorentz gas, K. Anderson and K. E. Shuler, J. Chem. Phys. 40, No. 3, 633-650 (Feb. 1, 1964).

As part of a study of the relaxation of non-equilibrium systems, the (translational) relaxation of a hard sphere Rayleigh and Lorentz gas is investigated. A master equation is formulated to represent the time variation of the distribution function of the sub-system particles and a technique is developed for transforming this integral master equation into differential Fokker-Planck equations. The Fokker-Planck equation for the Rayleigh gas is solved analytically and explicit solutions are presented for the relaxation of initial Maxwell and initial $\delta$-function distributions of the energy. The Fokker-Planck equation for the hard sphere Lorentz gas does not appear to be susceptible to an analytical solution in terms of orthogonal polynomials, but some general properties of the solution have been established.

Radiation-induced polymerization at high pressures, L, A. Wall and D. W. Brown, J. Polymer Sci.: Pt. C, No. 4, 11511160 (1963).

Several radiation-induced polymerization reactions were investigated at pressures between 5,000 and 17,000 atmospheres and temperatures between $20^{\circ} \mathrm{C}$ and $275{ }^{\circ} \mathrm{C}$. The most detailed studies have been with propylene and $n$-tetradecafluoroheptene-1. With both monomers the variation of rate of polymerization, $R_{p}$, with temperature and radiation intensity is consistent with a free radical mechanism. The maximum number of monomer units converted to polymer per 100 electron volts absorbed, $\mathrm{G}(\mathrm{M})$, is 108,000 and 7,600 in the polymerization of propylene and the heptene, respectively; thus, the kinetic chains are long. However, the number-average degree of polymerization, $D P_{n}$, is low, the maximum values being about 75 in both polymerization. In the polymerization of propylene, transfer to monomer limits $D P_{n}$; the transfer constant becomes greater as temperature increases or pressure decreases. In the polymerization of the heptene, $D P_{n}$ is determined by both transfer and termination. In the later polymerization both $R_{p}$ and $D P_{n}$ first increase and then decrease as the temperatures is raised at constant pressure because the depolymerization rate becomes appreciable at high temperature and reduces the observed $R_{p}$.

Pyrolysis of polytrifluoroethylene: influence of gamma radiation and alkali treatment, S. Straus and L. A. Wall, SPE Trans. 4, No. 1,61-65 (Jan. 1964).

Pyrolysis in vacuum of gamma-irradiated polytrifluoroethylene indicates increased rates of volatilization with increased dosage. At the higher radiation doses, the rate curves no longer show a maximum but resemble those previously obtained with branched polyethylenes.

Studies of swelling with acetone indicate crosslinking, which increases with radiation dose. It is estimated that for each chain fracture caused by radiation there are approximately seven crosslinks formed. However, in addition to the crosslinks a branched structure is also being produced as evidenced by the character of the thermal degradation rate curves. Alkali treatment of the polymer sensitizes it towards dehydrofluorination and double bond formation. Subsequent rate and pyrolysis studies showed the formation of very stable residues, indicating a relatively greater thermal stability of the main chain.
Two-crystal scintillation pair-spectrometer, B. Ziegler, J. M. Wyckoff, and H. W. Koch, Nuclear Instr. Methods 24, 301315 (Feb. 13, 1964).

A total absorption X-ray spectrometer has been developed in which a coincidence requirement selects only those $\mathrm{X}$-ray photons that have produced an electron-positron pair near the surface of a large sodium-iodide scintillation spectrometer. The X-ray energy resolution of the spectrometer that results is $2 \%$ and the detection efficiency is about $6 \%$ for $17.6 \mathrm{Mev}$ $\mathrm{Li}^{7}(p, \gamma)$ rays. Measurements and calculations of resolutions and efficiencies for 6 to $100 \mathrm{Mev}$ photons are given as well as an illustration of the spectrometer application to the measurement of synchrotron bremsstrahlung spectra transmitted by long absorbers.

The use of an analog computer in side-on arc spectroscopy, J. B. Shumaker, Jr., and C. R. Yokley, Appl. Opt. 3, No. 1, 83-87 (1964).

An analog computer which solves Abel's integral equation is described and its application to the side-on spectroscopic study of high current ares is illustrated. By its use radially resolved spectra of cylindrically symmetric inhomogeneous sources are obtained with the same speed and simplicity as are spectra of homogeneous sources. Comparison of NI transition probability measurements using this computer with those using conventional numerical radial resolution techniques indicates that the computer errors are negligible.

The direct determination of the crystal structure of $\mathbf{N a B}(\mathbf{O H})_{4} \cdot \mathbf{2 H}_{2} \mathbf{O}$, S. Block and A. Perloff, Acta Cryst. 16, No. 12, 1233-1238 (Dec. 1963).

The structure of $\mathrm{NaB}(\mathrm{OH})_{4} \cdot 2 \mathrm{H}_{2} \mathrm{O}$ has been determined by direct methods. Three-dimensional $\mathrm{Cu} K \alpha$ single-crystal data were used. The space group is $P \overline{1}, Z=2$ and the cell dimensions are:

$$
\begin{array}{ll}
a=6 \cdot 126 \pm 0.008 \AA & \alpha=67^{\circ} 55^{\prime} \pm 07^{\prime} \\
b=8.180 \pm 0.008 \AA & \beta=110^{\circ} 35^{\prime} \pm 07^{\prime} \\
c=6.068 \pm 0.008 \AA & \gamma=101^{\circ} 51^{\prime} \pm 07^{\prime}
\end{array}
$$

The structure consists of discrete tetrahedral $\mathrm{B}(\mathrm{OH}) \overline{4}$ groups and octahedrally coordinated sodium ions. An octahedron shares two edges to form chains parallel to the [100] direction. The chains are linked in the [001] direction by boron tetrahedra to form sheets parallel to the (010) face. Hydrogen bonds connect oxygen atoms within the sheet and link the sheets into a three-dimensional network. Bond distances and bond angles are presented and the application of the direct method is discussed.

Wave functions and oscillator strengths for the lithium isoelectronic sequence, A. W. Weiss, Astrophys. J. 138, No. 4, 1262-1246 (Nov. 16, 1963).

Hartree-Fock wave functions for the $1 s^{2} 2 s, 1 s^{2} 2 p, 1 s^{2} 3 s$, $1 s^{2} 3 p$, and $1 s^{2} 3 d$ configurations of the lithium isoelectronic sequence through $Z=10$ have been calculated. Oscillator strengths for all possible transitions between these levels were computed utilizing the dipole length, velocity, and acceleration forms of the transition matrix element. In addition, the $2 s-2 p$ transition has been calculated using a 45-term configuration interaction function for both states.

Thermal expansion of silver iodide, A. Bienenstock and G. Burley, J. Phys. Chem. Solids 24, 1271-1278 (Apr. 1963).

The thermal expansion of silver iodide with the zincblende structure has been measured by X-ray diffraction techniques in the temperature range 4.2 to $300^{\circ} \mathrm{K}$. Although dependent on sample preparation, it is negative to approximately $80^{\circ} \mathrm{K}$, positive in the range $80^{\circ} \mathrm{K}$ to $110{ }^{\circ} \mathrm{K}$, and then attains a constant negative high temperature value. This expansion is explained in terms of a model which shows the dependence of thermal expansion on structure and bonding. It is shown that the primary role of covalency, in its contribution to the low-temperature contraction, is to reduce the interaction between next-nearest neighbors. The particular form of the interatomic interaction appears to contribute primarily to the balance between modes with positive and negative 
Gruneisen factors. In the case of $\mathrm{AgI}$, it is the large $\mathrm{n}$ in the nearest neighbor repulsive interaction, $r^{-n}$, which accounts for the negative high temperature limit. The positive thermal expansion at intermediate temperatures is the result of transverse optical modes with lower frequencies than transverse acoustic modes.

Some properties of polystyrene networks formed from oriented chains, J. C. Halpin and L. Mandelkern, J. Polymer Sci.: Pt. B, 2, 139-142 (1964).

The increase in isotropic length, $L_{1}$, of highly oriented noncrystalline polystyrene fibers was studied so as to compare its behavior with that of previously studied crystalline polymers such as natural rubber and polyethylene. It was shown, as predicted by theory, that the high axial orientation imposed on the system prior to network formation, and not the crystallization in the polymer, is the prime requirement to produce a substantial increase in $L_{1}$. Subsequent to the initial shrinkage, reversible and reproducible length-temperature measurements could be made. The glass temperature, $T_{g}$, increases linearly with the degree of crosslinking.

Pair correlations in closed-shell systems, M. Krauss and A. W. Weiss, J. Chem. Phys. 40, No. 1, 80-85 (Jan. 1, 1964).

Pair function equations have been derived exactly for a restricted class of trial functions containing only closed shell pair correlations. In a matrix representation, it is shown that they reduce to a homogeneous pseudo-eigenvalue equation. The results are equally applicable to any set of unitarily transformed set of Hartree-Fock orbitals. Comparisons are made with the Sinanoglu scheme, and computational problems are discussed.

Microwave spectrum of lithium chloride, D. R. Lide, Jr., P. Cahill, and L. P. Gold, J. Chem. Phys. 40, No. 1, 156-159 (Jan, 1, 1964).

The rotational transitions $J=0 \rightarrow 1$ in the three lowest vibrational states of $\mathrm{Li}^{7} \mathrm{Cl}^{35}$ and the two lowest vibrational states of $\mathrm{Li}^{7} \mathrm{Cl}^{37}$ have been measured at a temperature of $600^{\circ}-800^{\circ} \mathrm{C}$. The molecular constants (in Mc/sec) for $\mathrm{Li}^{7} \mathrm{Cl}^{35}$ are: $B_{e}=21181.1 \pm 0.1, \alpha_{e}=240.2 \pm 0.2, \gamma_{e}=1.2 \pm 0.2$; those for $\mathrm{Li}^{7} \mathrm{Cl}^{37}$ are: $B_{e}=20989.9 \pm 0.1, \quad \alpha_{e}=236.9 \pm 0.2$. The internuclear distance is $r_{e}=2.02067 \pm 0.00006 \AA$. (The uncertainties represent maximum limits of error.) A combination of the present results with molecular beam electric resonance data yields a dipole moment $\mu_{v}=7.075+0.0885$ $(v+1 / 2)$ D for $\mathrm{Li}^{6} \mathrm{Cl}^{35}$. Two high-temperature microwave spectrometers of new design are described briefly. A tabulation of molecular constants for the complete series of alkali halide molecules is included.

Preparation and properties of difluoroborane, T. D. Coyle, J. J. Ritter, and T. C. Farrar, Proc. Chem. Soc. (London), p. 25 (Jan. 1964).

Difluoroborane $\left(\mathrm{HBF}_{2}\right)$, the first example of a partially fluorinated boron hydride, has been prepared by two routes. Some physical and chemical properties characterizing this compound are given.

Antireciprocity and memory in the statistical approach to irreversible thermodynamics, R. E. Nettleton, J. Chem. Phys. 40, No. 1, 112-116 (Jan. 1964).

The macroscopic state of a large, closed system is specified by the ensemble averages $\alpha_{j}$ of a set of even dynamical variables $A_{j}$, together with the averages $\nu_{j}$ of the quantities $i L A_{j}$, obtained by operating on the $A_{j}$ with the self-adjoint Liouville operator $L$. Phenomenological equations for the time rates of change, $\dot{\alpha}_{j}$ and $\dot{\nu}_{j}$, are derived by a technique due to Zwanzig, in which one operates on Liouville's equation with a projection operator which projects out the part which is "relevant" to the phenomenological description employed. These phenomenological equations are shown to exhibit the Onsager-Casimir reciprocity relations, including antisymmetry relations whose deviation is found to require a slight modification of Zwanzig's mathematical assumptions. Since $\nu_{i}=\dot{\alpha}_{j}$, these equations also show that irreversible thermodynamics can be extended to the case where second-order time derivatives appear representing memory effects, as well as nonlinear terms in the $\alpha_{j}$, provided the equations are still required to be linear in the $\nu_{i}$. Furthermore, Onsager's equations are obtained while allowing the phenomenological matrices to be functions of the variables $\alpha_{j}$, and not merely of constants of the motion. This serves to generalize and extend Zwanzig's earlier treatment.

Infrared spectra of $\mathrm{HNC}$ from 2000 to $3000 \mathrm{~cm}^{-1}$, A. G. Maki and L. R. Blaine, J. Mol. Spectry. 12, No. 1, 45-68 (Jan. 1, 1964).

New measurements are reported on eight vibration-rotation absorption bands of $\mathrm{HCN}$ in the infrared region from 2000 to $3600 \mathrm{~cm}^{-1}$. Comparison is made with the predictions of Rank et $a l$ and some revisions of rotational constants is found necessary. Perturbations due to $l$-type resonance are taken into account and found to be in very good agreement with the theory. The splitting of the $\Delta$ energy levels is found to be large enough to be observed at microwave frequencies.

Structure beyond the ionization limit in inelastic electron scattering in the rare gases, C. E. Kuyatt and J. A. Simpson, Proc. 6th Intern. Symp. Ionization Phenomena in Gases IA11, 33-35 (Paris, 1964).

The intensity of inelastic scattering of electrons with 500 to $1000 \mathrm{eV}$ primary energy by rare gases has been examined in an electron spectrometer with a resolution of $\sim 0.7 \mathrm{eV}$. At energies beyond the first ionization limit, structures localized in energy are detected. The structures in argon, neon, krypton, and xenon occur in a region a few eV below the $\mathrm{L}_{1}$, $\mathrm{M}_{1}, \mathrm{~N}_{1}$, and $\mathrm{O}_{1}$ ionization edges respectively, and probably correspond to discrete autoionizing states of the inner electron involved. The structure in helium has been discussed recently by Fano, and arises from interference between a two-electron autoionizing state and a continuum. Because energy losses corresponding to extreme ultraviolet transitions are easily accessible, electron scattering provides a versatile method for the study of effects far out in the continuum.

Absolute oscillator strengths for Fe I, C. H. Corliss and B. Warner, Astrophys. J. Suppl. Series No. 83, VIII, 395-438 (Feb. 1964).

Relative $g f$-values for 2000 lines of Fer between 3100 and 9900 $\AA$ from several investigations have been reduced to the absolute scale of the National Bureau of Standards tables of transition probabilities. They include new observations of faint lines in the visible and infrared portions of the spectrum.

\section{Other NBS Publications}

J. Res. NBS 68B (Math. and Math. Phys.), No. 2 (Apr.June 1964), 75 cents.

Determinations based on duplication of readings. J. A. Speckman.

General application of Youden's rank sum test for outliers and tables of one-sided percentage points. T. A. Willke. (See above abstracts.)

A generalization of Rennie's inequality. A. J. Goldman.

On the asymptotic joint normality of quantiles from a multivariate distribution. L. Weiss.

Fitting $y=\beta x$ when the variance depends on $x$. J. Van Dyke. (See above abstracts.)

Existence of k-edge connected ordinary graphs with prescribed degrees. J. Edmonds.

Inequalities for solutions of mixed boundary value problems for elastic plates. J. H. Bramble and L. E. Payne.

Radio Sci. J. Res. NBS/USNC-URSI 68D, No. 7 (July 1964). $\$ 1.00$.

Leader and junction processes in the lightning discharge as a source of VLF atmospherics. H. R. Arnold and E. T. Pierce.

The return stroke of the lightning flash to earth as a source of VLF atmospherics. A. S. Dennis and E. T. Pierce.

VLF propagation in a compressible ionosphere. R. B. Kieburtz.

A spectrographic interferometer. R. H. Lee and J. W. Warwick. (See above abstracts.)

Effect of lossy earth on antenna gain, part II. W. L. Curtis.

Calculation of groundwave attenuation in the far diffraction region. L. E. Vogler. 
Some numerical results based on the theory of radio wave propagation over inhomogeneous earth. K. Furutsu, R. E. Wilkerson, and R. F. Hartmann.

A note on VHF reflection from a tropospheric layer. J. R. Wait.

Some remarks on the use of statistics in radar astronomy, I. Kay.

A meteorological parameter for radioclimatological purposes. P. Misme.

Title page, contents and corrections, J. Res. 67A (Phy. and Chem.) (1963), 5 cents.

Title page, contents and corrections, J. Res. 67B (Math. and Math. Phys.) (1963), 5 cents.

Title page, contents and corrections, J. Res. 67C (Eng. and Instr.) (1963), 5 cents.

Title page, contents and corrections, J. Res. 67D (Radio Prop.) (1963), 10 cents.

1963 Research highlights of the National Bureau of Standards, NBS Misc. Publ. 255 (Dec. 1963), \$1.00.

An atlas of solar flare effects observed on long VLF paths during 1961, C. J. Chilton, F. K. Steele and D. D. Crombie, NBS Tech. Note 210 (Mar. 13, 1964), 30 cents.

Hot-rolled rail steel bars (produced from tee-section rails), CS150-63 (Dec. 15, 1963), 10 cents (Supersedes CS150-48).

Calculated diffraction effects at VLF from a localized ionospheric depression, J. R. Wait, NBS Tech. Note 208 (Jan. $16,1964), 15$ cents.

Sensitivity indices for Hall generators, S. Rubin and G. J. Rogers, NBS Tech. Note 233 (Feb. 6, 1964), 20 cents.

Soviet research in field emission, 1960-1963; an annotated bibliography, T. W. Marton and R. Klein, NBS Tech. Note 234 (Feb. 24, 1964), 30 cents.

Acrylonitrile-butadiene-styrene (ABS) plastic pipe (SDR-PR and Class T), CS254-63 (July 1, 1963), 10 cents.

Polyethylene (PE) plastic pipe (SDR-PR), CS255-63 (July $1,1963), 10$ cents.

Polyvinyl chloride (PVC) plastic pipe (SDR-PR and Class T) CS 256-63 (July 1, 1963), 10 cents.

Choking two-phase flow of hydrogen: Some idealized solutions, R. V. Smith, Proc. Nuclear Propulsion Conf., Aug. 15-17, 1962, Monterey, California, pp. 114-125 (1963).

Review of mode theory of radio propagation in terrestrial waveguides, J. R. Wait, Rev. Geophys. 1, No. 4, 481-505 (Nov. 1963).

First-order perturbation corrections to the Hartree-Fock approximation for helium, A. W. Weiss and J. B. Martin, Phys. Rev. 132, No. 5, 2118-2122 (Dec. 1, 1963).

The propagation time of a radio pulse, J. R. Johler, IEEE Trans. Ant. Prop. AP-11, No. 6, 661-668 (Nov. 1963).

Incoherent inelastic neutron scattering and self-diffusion, R. Zwanzig, Phys. Rev. 133, No. 1A, A50-A51 (Jan. 6, 1964).

Radiometry, M. M. Reynolds, R. J. Corruccini, M. M. Fulk and R. M. Burley, Am. Inst. Phys. Handb. 2d ed. 6-1536-172 (McGraw-Hill Book Co. Inc., New York, N.Y., 1963).

The ionization constant of $m$-nitrophenol from 5 to $50^{\circ}$ R. A. Robinson and A. Peiperl, J. Phys. Chem. 67, 2860 (1963).

Transition array for $d^{3} \rightarrow d^{2} p$ : Vanadium III, H. Mendlowitz, Astrophys. J. 138, No. 4, 1277-1296 (Nov. 15, 1963).

Behavior of filamentous materials subjected to high-speed tensile impact, J. C. Smith, C. A. Fenstermaker, and P. J. Shouse, Symp. Dynamic Behavior of Materials, ASTM Spec. Tech. Publ. 336, 47-69 (1962).

Interlaboratory evaluation of procedures for tongue-tearing strength of woven fabrics, E. B. Randall, Jr., Mater. Res. Std. 4, No. 2, 53-61 (Feb. 1964)

Calorimetry, G. T. Armstrong, Phys. Today 1\%, No. 2, 50-54 (Feb. 10, 1964) ; Science 143, No. 3602, 158-163 (Jan. 10, 1964).

Note on the 4-body system, T. Stovall and M. Danos, Physics Letters 7, No. 4, 278-281 (Oct. 23, 1963).

Observation of optically forbidden transitions in the continuum of the rare gases by electron energy loss measurements, J. A. Simpson, S. R. Mielezarek, and J. Cooper, J. Opt. Soc. Am. 54, No. 2, 269-270 (Feb. 1964).
The standard potential of the silver-silver chloride electrode in water-mannitol solutions at $25^{\circ}$, M. Paabo and R. A. Robinson, J. Phys. Chem. 67, 2801 (1963).

On the nature of the crystal field approximation. II. Numerical results, R. T. Berger and C. M. Herzfeld, J. Chem. Phys. 39, No. 4, 1122-1126 (Aug. 15, 1963).

Normal congruence subgroups of the modular group, M. Newman, Am. J. Math. LXXXV, No. 3, 419-427 (July 1963).

Calibration of potentiometers by resistance bridge methods, D. Ramaley, Instr. Control Systems 37, 106-108 (Jan. 1964).

International symposium on the solar spectrum, Utrecht, 26-31, August 1963, C. E. Moore, Appl. Opt. 3, No. 1, 12 (Jan. 1964).

Penetration of protons, alpha particles, and mesons, U. Fano, Ann. Rev. Nuclear Sci. 13, 1-66 (Dec. 1963).

Empirical rules for predicting ground-state spins of light nuclei, T. Stovall, Phys. Rev. 133, No. 2B, B268-B269 (Feb. 27, 1964).

The melting (contraction) and recrystallization of fibrous proteins in nonaqueous media, L. Mandelkern, G. Canty, and A. F. Diorio, J. Phys. Chem. 6\%, No. 12, 2882-2884 (Dec. 1963).

Very-low-frequency radio waves and the ionosphere, D. D. Crombie, Science 142, No. 3591, 508-510 (Oct. 1963).

Mass spectrometric study of the recombination of bromine and chlorine atoms on pyrex, J. T. Herron, J. Phys. Chem. 6\%, 2864 (Dec. 1963).

Coulomb scattering without atomic excitation for 50-, 100-, 200-, and 400-KeV electrons, J. W. Motz, R. C. Placious, and C. E. Dick, Phys. Rev. 132, No. 6, 2558-2561 (Dec. $15,1963)$.

Effect of additives on the ionic reaction mechanism in the radiolysis of methane, P. Ausloos, S. G. Lias, and R. Gorden, Jr., J. Chem. Phys. 39, No. 12, 3341-3348 (Dec. $15,1963)$.

Inductive voltage dividers with calculable relative corrections, T. L. Zapf, C. H. Chinburg, and H. K. Wolf, IEEE Trans. Instr. Meas. IM-12, No. 2, 80-85 (Sept. 1963).

The meaning of "least" in least squares, C. Eisenhart, J. Wash. Acad. Sci. 54, No. 2, 24-33 (Feb. 1964)

Studies in scientific and engineering manpower. Part I. Patterns of utilization of scientific and engineering manpower in the United States and certain foreign countries. Part II. Trends in salaries of scientists and engineers, 1948-1962, M. S. Green, U. S. Department of Commerce, Office of the Assistant Secretary of Commerce for Science and Technology Staff Report: 63-1 (Oct. 1963), 40 cents.

Thermal conductivity, R. L. Powell, Am. Inst. Phys. Handb. 2d ed. 4-77-4-101 (McGraw-Hill Publ. Book Co. Inc., New York, N.Y., 1963).

Thermal stability of bis(8-hydroxy-5-quinolyl) methane co-ordination polymers, E. Horowitz and T. P. Perros, J. Inorg. Nucl. Chem. 26, 139-159 (1964).

Salt effects and medium effects on indicator acid-base equilibria in a methanol-water solvent, D. Rosenthal, H. B. Hetzer, and R. G. Bates, J. Am. Chem. Soc. 86, 549-554 (Feb. 20, 1964)

Theory of irreversible processes in a plasma-derivation of a convergent kinetic equation from the generalized master equation, J. Weinstock, Phys. Rev. 133, No. 3A, A673A680 (Feb. 1964).

English translation of the book, Vapor Pressure of the Chemical Elements, by A. N. Nesmeyanov, Editor, R. Gary, 462 pages (Elsevier Publ. Co., New York, N.Y., 1964).

Photolysis of cellulose in a vacuum with 2537 A light, J. H. Flynn and W. L. Morrow, J. Polymer Sci.: Pt. A2, 81-89 (1964)

Use of photographic film for personnel dosimetry; basic physical considerations, M. Ehrlich, Symp. Personnel Dosimetry Techniques for External Radiation, Apr. 1-5, 1963, Madrid Spain, pp. 49-74 (Dec. 1963).

On an extreme rank sum test for outliers, W. A. Thompson, Jr., and T. A. Wilke, Biometrika 50, No. 3-4, 375-383 (1963) 
Theoretical studies on signal-to-noise characteristics of an FM system, H. Akima, IEEE Trans. Space Electron. Telemetry SET-9, No. 4, 101-108 (Dec. 1963).

Translational dispersion in gases, M. Greenspan, Estratto da Rendiconti della Scuola Internazionale di Fisica, E. Fermi XXVII Corso, 73-100 (1963).

Preparation of lantern slides, L. S. Taylor, Health Phys. J. 9, No. 10, 1009-1011 (Oct. 1963).

A survey of ionospheric effects upon earth-space radio propagation, R. S. Lawrence, C. G. Little, and H. J. A. Chivers, Proc. IEEE 52, No. 1, 4-27 (Jan. 1964).

Statistical thermodynamics of the lattice model of a polymer molecule, J. Mazur, J. Chem. Phys. 40, No. 4, 1001-1007 (Feb. 15, 1964).

Standards, sources, and detectors in radiation measurements, R. Stair and W. E. Schneider, Symp. Thermal Radiation of Solids, Session III. Measurement Techniques, (San Francisco, Calif., Mar. 4-6, 1964), Paper 3 (1964).

Problems in the application of norms of external radiation, L.S. Taylor, Symp. Personnel Dosimetry Techniques for External Radiation, Madrid Spain, Apr. 15, 1963, pp. 35-47 (1963).

Some aspects of the mechanical properties of high polymers, H. Leaderman, (Proc. Conf. Mechanical Properties of Wood, Univ. of Calif., Berkeley, Calif., Aug. 27-Sept. 1, 1962), Book, The Mechanical Behavior of Wood, pp. 43-83 (1963).

Pyrolysis of new fluoropolymers, S. Straus and L. A. Wall, SPE Trans. 4, No. 1, 56-60 (Jan. 1964).

The surface composition of hydroxylapatite derived from solution behavior of aqueous suspensions, V. R. Deitz, H. M. Rootare, and F. G. Carpenter, J. Colloid Sci. 19, No. 1, 87-101 (Jan. 1964).
The gas phase radiolysis of propane. Effect of pressure and added inert gases, P. Ausloos, S. G. Lias, and I. B. Sandoval, Discussions Faraday Soc. No. 36, pp. 66-74 (1963).

Impact noise in multi-family dwellings, R. D. Berendt, Bldg. Res. 1, No. 1, 40-42 (Jan.-Feb. 1964).

Second acid dissociation of N,N-Di-(2-hydroxyethyl)-glycine and related thermodynamic quantities from 0 to $55^{\circ}$, S. P. Datta, A. K. Grzybowski and R. G. Bates, J. Phys. Chem. 68, No. 2, 275-280 (Feb. 1964).

Effects of deuteration and temperature upon the photolysis of cellulose in a vacuum with 2537 A light, J. H. Flynn and W. L. Morrow, J. Polymer Sci.: Pt. A, 2, 91-103 (1964).

Concentration-dependent diffusion coefficient of water in glass, W. Haller, Phys. Chem. Glasses 4, No. 6, 217-220 (Dec. 1963).

Polarons in an electric field, D. M. Larsen, Phys. Rev. 133, No. 3A, A860-A866 (Feb. 3, 1964).

The effect of carbon-arc intensity on asphalt oxidation, J. R. Wright, P. G. Campbell, and T. L. Fridinger, J. Appl. Chem. 14, 30-35 (Jan. 1964).

Statistics in its proper place, W. J. Youden, J. Wash. Acad. Sci. 54, 53-57 (1964).

Spectroradiometry by means of modified spectrophotometers, H. K. Hammond III, Appl. Opt. 2, No. 11, 1207-1208 (Nov. 1963).

*Publications for which a price is indicated are available by purchase from the Superintendent of Documents, U.S. Government Printing Office, Washington, D.C., 20402 (foreign postage, one-fourth additional). Reprints from outside journals and the NBS Journal of Research may often be obtained directly from the authors. 